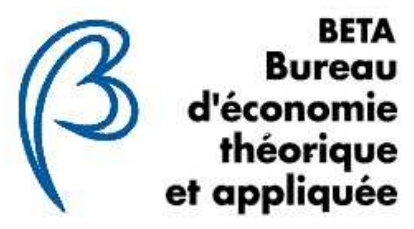

\title{
« Endogenous heterogeneity in duopoly with deterministic one-way spillovers »
}

\author{
$\underline{\text { Auteurs }}$ \\ Adriana Gama, Isabelle Maret, Virginie Masson
}

Document de Travail $n^{\circ} 2018-23$

Mai 2018

Bureau d'Économie

Théorique et Appliquée

BETA Université de Strasbourg

Faculté des sciences économiques

et de gestion

61 avenue de la Forêt Noire

67085 Strasbourg Cedex

Tél. : +33 (0)3 68852069

Fax : +33 (0)3 68852070

Secrétariat : Géraldine Del Fabbro

g.delfabbro@unistra.fr 


\title{
Endogenous heterogeneity in duopoly with deterministic one-way
}

\section{spillovers*}

\author{
Adriana Gama ${\text { Isabelle Maret }{ }^{\ddagger} \text { and Virginie Masson }}^{\S}$
}

May 16, 2018

\begin{abstract}
This paper examines the standard symmetric two-period R\&D duopoly model, but with a deterministic one-way spillover structure. Though the two firms are ex-ante identical, one obtains a unique pair of asymmetric equilibria of $R \& D$ investments, leading to inter-firm heterogeneity in the industry, in R\&D roles as well as in unit costs. We analyze the impact of a change in the spillover parameter and $R \& D$ costs on firms' levels of $R \& D$ and profits. We find that higher spillovers need not lead to lower R\&D investments for both firms. In addition, equilibrium profits may improve due to the presence of spillovers, and it may be advantageous to be the $R \& D$ imitator rather than the $R \& D$ innovator.
\end{abstract}

Key words and phrases: One-way Spillovers, asymmetric R\&D equilibria, R\&D and interfirm heterogeneity, symmetry-breaking.

JEL codes: D45, L10, C72.

\footnotetext{
${ }^{*}$ The authors are grateful to Rabah Amir for many helpful conversations on the topic of this paper. This research was partially financed by the "Cercle Gutenberg" via the "Chaire Gutenberg : On environmental R\&D and Imperfect Competition" at the University of Strasbourg, France.

${ }^{\dagger}$ Centro de Estudios Económicos, El Colegio de México, Mexico (e-mail: agama@colmex.mx).

${ }^{\ddagger}$ Université de Strasbourg, CNRS, BETA UMR 7522, F - 67000, Strasbourg, France (e-mail: maret@unistra.fr)

${ }^{\S}$ School of Economics, The University of Adelaide, Australia 5005 (e-mail: virginie.masson@adelaide.edu.au)
} 


\section{Introduction}

The importance of the imperfect appropriability of research and development (henceforth R\&D) is well understood and amply reflected in the recent literature on R\&D in industrial organization. Spence's (1984) pioneering work on $R \& D$, market performance and public policy introduced the idea of a constant spillover parameter as a practical and tractable way of modeling appropriability of research and development R\&D. In his model, a constant proportion of each firm's R\&D expenditure flows freely to all the rival firms. This constant proportion is itself defined as the spillover parameter, postulated to lie in the unit interval, with the end values of 0 and 1 corresponding respectively to R\&D being a purely private good and a purely public good. Much of the follow up literature adopted this convenient modeling trick in investigating further the role of spillovers in imperfectly competitive markets with R\&D as a strategic variable. See Ruff (1969), Katz (1986), d'Aspremont and Jacquemin (1988, 1990), Kamien et al. (1992), Amir (2000), and Amir, Evstigneev and Wooders (2003), among many others. ${ }^{1}$

While the follow up literature deals primarily with the issue of $R \& D$ cooperation, the underlying non-cooperative benchmark scenario for strategic $\mathrm{R} \& \mathrm{D}$ is a standard two-stage game where firms choose process R\&D levels in the first stage, and then Cournot outputs in the second stage. Starting with Ruff (1969) and Spence (1984), most of the extant literature on imperfectly appropriable R\&D focuses on multidirectional R\&D spillovers, modeled as a constant parameter. Instead, Amir and Wooders (1999), henceforth AW, consider a stochastic directed spillover process whereby knowhow may flow only from the more R\&D intensive firm to its rival. ${ }^{2}$ In their model, spillovers are stochastic and admit only binary realizations - either full or no spillovers occur, with the probability of full spillovers itself being the new spillover parameter. ${ }^{3}$

As argued in some detail by AW, the idea underlying the assumption of a unidirectional spillover process is that it may better approximate the potential leakages that occur when the $R \& D$ process is well-approximated by one-dimensional research path. In other words, the trial and error process of R\&D can be captured by a motion of successive linearly ordered tests that need to be performed

\footnotetext{
${ }^{1}$ The literature on R\&D cooperation has more recently been extended to other areas of economics, including environmental innovation (McDonald and Poyago-Theotoky, 2017), the organization of the firm (Chalioti, 2015).

${ }^{2}$ That spillovers are an important aspect of firms' overall business strategy is well-documented (see e.g., Billand et al. (2016) for an overview of the related literature).

${ }^{3}$ For related settings, see also Amir and Wooders (2000), Jin and Troege (2006), and Tesoriere (2008).
} 
in order to derive new know how that will permit the firm to reduce its production (unit) cost. Alternatively, instead of an unambiguous single research path to achieve cost reductions, the firm may face a multi-dimensional path, but then the one-way spillover structure suggests that there is a more or less natural path to follow even though it may occasionally call for jumping from one branch of the search tree to another. In this context, the spillover parameter may be interpreted as being related to the length of patent protection, but also to a measure of the imitation lag.

The purpose of the present paper is to examine the certainty-equivalent of AW's model in the sense that a fraction of the R\&D undertaken by the leader (defined as the more R\&D-intensive firm) flows to its rival with certainty. In other words, we consider the standard two-period model of process $R \& D$ and product market competition with deterministic one-way spillovers. We adopt the common specification of linear market demand and identical linear cost functions for output production by the firms. Thus, in contrast to AW's model, the two-stage game model under consideration here is fully deterministic. The model we obtain is the same as the one considered in the recent study by Cosandier, De Feo and Knauff (2017), who focus on the performance of R\&D cooperation and on a detailed welfare analysis for this model.

We now provide a brief preview of the results of the present paper. Though firms are ex-ante identical, one obtains a unique pair of asymmetric equilibria so that the roles of R\&D innovator or leader (the more $R \& D$ intensive firm) and imitator or follower (the less $R \& D$ intensive firm) are endogenously determined. This a direct consequence of the structure of the firms' reaction curves, which have two segments separated by a downward jump that skips the $45^{\circ}$ line. In addition, the reaction curve is a downward-sloping line to the left of this discontinuity and an upward-sloping line to the right of this discontinuity for large spillovers. Hence, for large spillovers, the game is no longer one of strategic substitutes in a global sense such as in AW's model. ${ }^{4}$ This means that the strategic effect induced by an increase in the spillover parameter on the imitator's R\&D expenditures is reversed, i.e. the strategic effect reinforces the direct effect (in contrast to AW's model). Intuitively, the larger fraction that flows to the imitator compensates for the innovator's

\footnotetext{
${ }^{4}$ This is a priori an important difference between the two models. Indeed, it is an immediate consequence of the basic results from the theory of supermodular games that the AW model always possesses a subgame-perfect equilbrium, simply due to the fact that the R\&D game is of strategic substitutes. The same does not extend to the present model, at least not with further assumptions. Therefore, generalizing the present results to a broader formulation might well be a very challenging task. This justifies restricting attention to the case of linear demand and costs, and quadratic R\&D costs.
} 
lower level of investment so that free riding over the innovator's investment is more profitable than undertaking its own R\&D. Hence, in contrast to AW's model, for large spillovers, the imitator's level of R\&D always decreases with the spillover parameter.

This structure of the reaction curves reflects the fact that a firm always either spends less than its rival so as to free ride on the latter's R\&D investment through spillovers, or spends more if the other firm's investment is too low in order to benefit from a competitive advantage over its rival in the product market. This equilibrium outcome naturally leads to asymmetries in terms of the unit cost structure in the product market competition, and thus unequal market shares. This conclusion establishes a simple link between the nature of the R\&D process in an industry including the associated spillover - and the emergence of inter-firm heterogeneity in that industry.

We examine how R\&D investments and firms' profits vary with both the spillover parameter and the R\&D cost parameter. In particular, although both firms' reaction curves shift down as the spillover rate increases, we identify separate conditions for each firm's R\&D levels to increase in the spillover parameter. Nevertheless, if either demand is high enough relative to initial unit costs or R\&D costs are sufficiently convex, $R \& D$ expenditures globally decrease with the spillover parameter. Furthermore, we find that an increase in the spillover rate sometimes raises the innovator's profit and lowers that of the imitator. The industry is nonetheless better off with some degree of imperfect appropriability of R\&D as compared to no spillovers when R\&D costs are high.

This paper joins an extensive strand of literature in industrial organization and other fields in economics that considers the broad issue of symmetry-breaking, ${ }^{5}$ or how an endogenous form of heterogeneity of economic agents can naturally emerge out of a strategic situation involving an economic interaction between ex ante identical agents. A short list of such studies includes the following: See, inter alia, Matsuyama (2002), Soubeyran and Van Long (1999), Salant and Shaffer (1998, 1999), Amir, Garcia and Knauff (2010), Basu, Basu and Cordella (2016), Acemoglu et. al. (2017), and Chatterjee (2017).

One aspect of the choice between this paper with its deterministic spillover process and AW with its stochastic analog is motivated by the ease of comparison with the deterministic multiway spillover processes typically used in the literature (as in d'Aspremont and Jacquemin, 1988, Kamien, Muller and Zang, 1992, and Amir, 2000). ${ }^{6}$ Another difference between this setting and

\footnotetext{
${ }^{5}$ The phrase "symmetry-breaking" is borrowed from theoretical physics.

${ }^{6}$ More recent studies include Martin (2002), Chalioti (2015), Tesoriere (2008), Stepanova and Tesoriere (2011),
} 
the stochastic version in AW is that endogenous heterogeneity of firms in terms of R\&D and final unit costs holds with certainty in the present setting, but only with positive probability in the AW model.

The rest of the paper is organized as follows. Section 2 describes the model and the assumptions. Section 3 characterizes the equilibrium under R\&D competition. Section 4 studies the effect of a change in the spillover parameter and the $R \& D$ costs on firms' propensity to invest and profits. Concluding remarks are provided in Section 5. Finally, the proofs of our results are relegated to the Appendix.

\section{The model}

Consider a Cournot industry with two firms producing a homogenous good with the same initial unit $\operatorname{cost} c$, playing the following two-stage $\mathrm{R} \& \mathrm{D} /$ product market game. In the first stage, the two firms simultaneously decide on their autonomous cost reduction levels $x_{1}$ and $x_{2}$, with $x_{i} \in[0, c], i=1,2$. The $\mathrm{R} \& \mathrm{D}$ cost to firm $i$ associated with the cost reduction $x_{i}$ is $\frac{\gamma}{2} x_{i}^{2}, i=1,2$. So far, this formulation is very standard in the literature on process R\&D. The novelty in the present paper is due to the manner in which $R \& D$ spillovers are modeled.

We assume, following AW, that the innovation only flows from the more R\&D intensive firm (the innovator) to its rival (the imitator). But contrary to AW, we assume that the spillover process is deterministic. Namely, if autonomic cost reductions are $x_{1}$ and $x_{2}$ with, say, $x_{1} \geq x_{2}$, then the effective cost reductions are

$$
\left\{\begin{array}{l}
X_{1}=x_{1} \\
X_{2}=x_{2}+\beta\left(x_{1}-x_{2}\right)
\end{array}\right.
$$

where the parameter $\beta \in[0,1]$ is the fraction of the cost reduction undertaken by firm 1 that spills over firm 2 with certainty. Hence, $x_{2}+\beta\left(x_{1}-x_{2}\right)$ is now the firm 2's effective cost reduction while it was its expected value in AW. By symmetry, the analogous expressions hold for the case $x_{1} \leq x_{2}$.

In the second stage, upon observing the new unit costs, firms compete in the product market Burr, C., Knauff, M., Stepanova, A. (2013), and McDonald and Poyago-Theotoky (2017), among others. 
by choosing quantities, with linear inverse demand

$$
P\left(q_{1}+q_{2}\right)=a-\left(q_{1}+q_{2}\right)
$$

A pure strategy for firm $i$ is thus a pair $\left(x_{i}, q_{i}\right)$, where $x_{i} \in[0, c]$ and $q_{i}:[0, c]^{2} \rightarrow \mathbb{R}_{+}$. Throughout, we use the standard concept of subgame perfect equilibrium.

We assume that demand is sufficiently high relative to the initial unit cost so that, no matter what $R \& D$ levels are chosen by firms, the second-stage game admits a unique pure strategy Nash equilibrium (PSNE) where both firms are active in the product market.

(A1) $a>2 c$

The Cournot equilibrium profit function of firm $i$ in the second stage, in terms of the actual unit costs $c_{i}, c_{j}$, is thus given by

$$
\Pi\left(c_{i}, c_{j}\right)=\frac{\left(a-2 c_{i}+c_{j}\right)^{2}}{9} .
$$

Firms' net profits $F_{1}, F_{2}$, defined as the difference between the second stage profit and the first stage $R \& D$ investment, can then be expressed as functions of the autonomous cost reductions $x_{1}$ and $x_{2}$. Since the game is symmetric, we have that $F_{1}\left(x_{1}, x_{2}\right)=F_{2}\left(x_{2}, x_{1}\right)$. Therefore, throughout the paper, we omit the subscripts and write $F\left(x_{i}, x_{j}\right)$ to denote the net profit of firm $i$, where

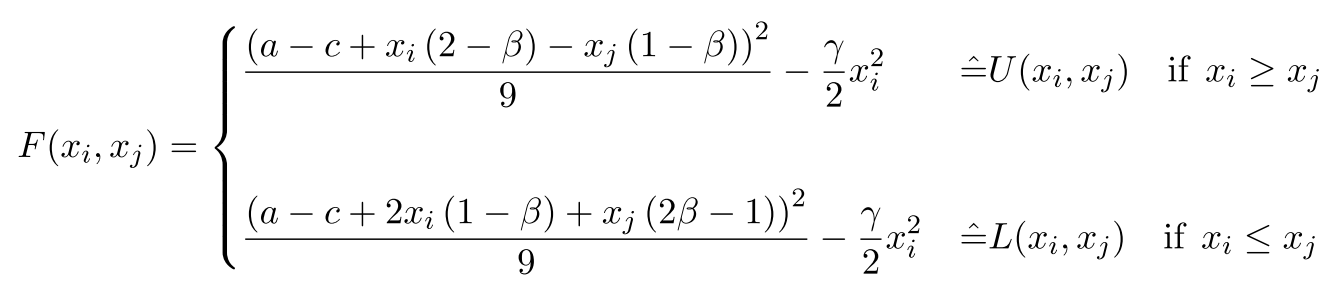

One can easily check that $F$ is continuous and nonconcave along the diagonal. Furthermore, for $\beta \leq \frac{1}{2}$, both $U$ and $L$ are submodular in $\left(x_{i}, x_{j}\right)$, i.e., $\frac{\partial^{2} U\left(x_{i}, x_{j}\right)}{\partial x_{i} \partial x_{j}}<0$ and $\frac{\partial^{2} L\left(x_{i}, x_{j}\right)}{\partial x_{i} \partial x_{j}}<0$. On the other hand, for $\beta>\frac{1}{2}, U$ is submodular but $L$ is supermodular in $\left(x_{i}, x_{j}\right)$, i.e., $\frac{\partial^{2} U\left(x_{i}, x_{j}\right)}{\partial x_{i} \partial x_{j}}<0$ and $\frac{\partial^{2} L\left(x_{i}, x_{j}\right)}{\partial x_{i} \partial x_{j}}>0$

Furthermore, we assume the following second-order type conditions (versions of these are standard in the literature on strategic $R \& D)$.

(A2) $9 \gamma>2(2-\beta)^{2}$ 
(A3) $9 \gamma>4 \frac{a}{c}(1-\beta)$

(A2) guarantees that $U$ and $L$ are strictly concave with respect to the first variable, so that the first-order condition is sufficient for optimality. (A3) is an interiority condition, in that it ensures that firm $i$ 's reaction function satisfies $r_{i}(c)<c$, where

$$
r_{i}\left(x_{j}\right) \in \operatorname{argmax}\left\{F\left(x_{i}, x_{j}\right): x_{i} \in[0, c]\right\} .
$$

This enables us to derive the reaction function of, say, firm $i$ as

$$
r_{i}\left(x_{j}\right)= \begin{cases}2 \frac{(2-\beta)\left(a-c+x_{j}(\beta-1)\right)}{9 \gamma-2(\beta-2)^{2}} & \text { if } x_{i} \geq x_{j} \\ 4 \frac{(1-\beta)\left(a-c+x_{j}(2 \beta-1)\right)}{9 \gamma-8(\beta-1)^{2}} & \text { if } x_{i} \leq x_{j}\end{cases}
$$

Since the game is symmetric, both firms have the same reaction curve (see Figure 1 for the reaction curves and Figure 2 for the parameter regions delineated by the above assumptions ${ }^{7}$ ).

\section{$3 \quad$ Equilibrium analysis}

This section provides the analysis of the subgame perfect equilibria of the two stage game. To do so, we proceed by viewing the game with payoffs as given in (1), and solve for the equilibrium R\&D levels.

Before characterizing the equilibrium investments of the first-stage $R \& D$ game, it is important to understand the special structure of the reaction curves. Our first result provides the key properties of firms' reaction functions.

Lemma 1. The reaction functions admit a unique downward jump, which skips the $45^{\circ}$ line.

An important direct consequence is that, despite the symmetry of the game, no symmetric Nash equilibrium in pure strategies can exist. ${ }^{8}$

Figure 1a (resp. 1b) depicts firms' reaction curves for $\beta \leq \frac{1}{2}$ (resp. $\beta>\frac{1}{2}$ ). As was previously mentioned, the upper payoff function $U$ is globally submodular in own and rival's decisions so

\footnotetext{
${ }^{7}$ Figure 2 has been drawn with values $\frac{a}{c}=2.2$.

${ }^{8} \mathrm{As}$ is well-known from general existence results in game theory, there exists of course a symmetric mixed-stragegy equilibrium since payoffs are jointly continuous in the actions and stategy spaces are compact intervals. Nevertheless, even under such a symmetric equilibrium, firms would end up getting different realizations of their unit costs.
} 
that it gives rise to a reaction function segment that shifts down as rival's investment increases. As for the lower payoff function $L$, it is also submodular in own and rival's decision for $\beta \leq \frac{1}{2}$, but supermodular for $\beta>\frac{1}{2}$, so that its reaction function segment shifts up as rival's investment increases for this range of the spillover parameter. In contrast to our model, each player's payoff function in AW is instead globally submodular in $\left(x_{i}, x_{j}\right)$ so that reaction curves have a similar character to those depicted in Figure 1a (see Appendix 1).

In other words, the innovator always responds to a variation of its rival's $R \& D$ investment by a variation in the opposite direction of its own levels of $R \& D$, independently of the value of the spillover parameter $\beta$. Although the imitator reacts in a similar way for values of $\beta \leq \frac{1}{2}$, its response changes for $\beta>\frac{1}{2}$, whereby a decrease in the innovator's $R \& D$ levels is met with a decrease in $\mathrm{R} \& \mathrm{D}$ by the imitator. This intuitively can be explained by the fact that as $\beta>\frac{1}{2}$, the innovator's incentive to invest in $R \& D$ decreases as investment becomes less appropriable. If the imitator were then to follow a decrease in $R \& D$ investment from its rival by an increase in its own $R \& D$ levels, the innovator will respond by decreasing further its own investment, thus diminishing the benefit received by the imitator from the high value of the spillover parameter $\beta$. It is therefore beneficial for the imitator to follow the decrease of the innovator's investment to prevent further reduction in the innovator's R\&D levels. This contrasts sharply with AW and is due to the certainty regarding the value of $\beta$ and its guaranteed benefits to the imitator when $\beta$ is high enough.

Given firms' reaction functions as derived in the previous section, straightforward computations establish that the two reaction curves cross at a pair of (symmetric) points $(\bar{x}, \underline{x})$ and $(\underline{x}, \bar{x})$, where

$$
\begin{aligned}
\bar{x} & =\frac{2(a-c)(2-\beta)\left(3 \gamma-4(\beta-1)^{2}\right)}{27 \gamma^{2}-6 \gamma\left(5 \beta^{2}-12 \beta+8\right)+8(2-\beta)(1-\beta)^{2}} \\
\underline{x} & =\frac{4(a-c)(1-\beta)(3 \gamma-2(1-\beta)(2-\beta))}{27 \gamma^{2}-6 \gamma\left(5 \beta^{2}-12 \beta+8\right)+8(2-\beta)(1-\beta)^{2}} .
\end{aligned}
$$

It is easy to verify that $\bar{x}>\underline{x}$ for any $\beta \in(0,1)$.

To guarantee that these two points lie in the interior of the area of interest, i.e., in $(0, c) \times(0, c)$, we need the following additional assumption

(A4) $9 \gamma>I(\beta)$ 
where

$$
\begin{aligned}
I(\beta)= & \left(\frac{a}{c}-1\right)(2-\beta)+\left(5 \beta^{2}-12 \beta+8\right) \\
& +\sqrt{\left(\left(\frac{a}{c}-1\right)(2-\beta)+\left(5 \beta^{2}-12 \beta+8\right)\right)^{2}-24 \frac{a}{c}(2-\beta)(1-\beta)^{2}}
\end{aligned}
$$

Though firms are ex-ante identical, the next proposition establishes the existence of only asymmetric equilibrium pairs of $R \& D$ investments. This gives rise endogenously to a high $R \& D$ firm (called the innovator in AW) and a low R\&D firm (called the imitator in AW).

Proposition 1. Suppose that (A1) through (A4) hold. The RED game admits a unique pair of PSNE of the form $(\bar{x}, \underline{x})$ and $(\underline{x}, \bar{x})$.

As in the stochastic version of the model, the equilibrium levels of $R \& D$ investments are necessarily asymmetric, due to the nonconcavity of the net profit function $F$ along the $45^{\circ}$ line. By Lemma 1, reaction curves jump downward over the diagonal at $\widehat{x}$ as indicated on Figure 1. Therefore, in equilibrium, a firm will always either spend less than its rival so as to free ride on the latter's R\&D investment through spillovers, or spend more if the other firm's investment is too low in order to benefit from a competitive advantage over its rival in the product market. Notice that (A4) ensures that the two equilibrium pairs $(\bar{x}, \underline{x})$ and $(\underline{x}, \bar{x})$ are interior solutions.

Instead, if (A1) through (A3) are satisfied, but (A4) is not, we have a boundary equilibrium of the form $\left(\bar{x}^{B}, \underline{x}^{B}\right)$ and $\left(\underline{x}^{B}, \bar{x}^{B}\right)$ where $\bar{x}^{B}=c$ and $\underline{x}^{B}=4 \frac{(a-2 c(1-\beta))(1-\beta)}{9 \gamma-8(\beta-1)^{2}}$. Figure 2 graphs assumptions (A2) through (A4) in the parameter space $(\beta, 9 \gamma)$ and shows whether an interior or a boundary equilibrium prevails.

The two extreme values of the spillover parameter $\beta$ deserve to be discussed separately. The minimal value $\beta=0$ captures the fact that $R \& D$ is a pure private good, in which case the equilibrium autonomous and effective $R \& D$ levels reduce to

$$
\bar{x}=\underline{x}=X_{1}=X_{2}=\frac{4(a-c)}{9 \gamma-4} .
$$

It is easy to see in this case that the model at hand coincides with the usual model with multidimensional spillovers with $\beta=0$, as in d'Aspremont and Jacquemin $(1988,1990)$, Kamien et al. (1992), and Amir (2000). Therefore, for this extreme value of the spillover parameter $\beta$, the subgame-perfect equilibrium is symmetric and there is no ex post heterogeneity. 
When $\beta=1, R \& D$ may be seen as a pure public good, and the equilibrium autonomous and effective R\&D levels, which reflect complete free-riding on the part of the follower (firm 2) as one would expect, are $^{9}$

$$
\begin{aligned}
\bar{x} & =\frac{2(a-c)}{9 \gamma-2}, \underline{x}=0 \text { and } \\
X_{1} & =X_{2}=\frac{2(a-c)}{9 \gamma-2} .
\end{aligned}
$$

It is quite intuitive that, for this extreme value of the spillover parameter $\beta$, the subgameperfect equilibrium is not only asymmetric, but calls for the follower to conduct no R\&D at all and to completely free ride on the leader's R\&D; thus one may talk of maximal ex post heterogeneity in this case in terms of the $R \& D$ expenditures and net profits since the innovator is the only one to support the R\&D costs. Nevertheless, the two firms end up with identical marginal cost of production and produce the same quantity in the second stage, i.e.

$$
\begin{aligned}
& c_{1}=c_{2}=c-\frac{2(a-c)}{9 \gamma-2}=\frac{9 \gamma c-2 a}{9 \gamma-2} \\
& q_{1}^{*}=q_{2}^{*}=\frac{a-\frac{9 \gamma c-2 a}{9 \gamma-2}}{3}=\frac{3 \gamma(a-c)}{9 \gamma-2}
\end{aligned}
$$

This corresponds to the market structure introduced by Kamien, Muller and Zang (1992) where all firms form a Research Joint Venture, share R\&D efforts and avoid duplication of R\&D activities. Nevertheless, they still compete; each firm decides its own R\&D level given the R\&D investment of its competitor.

\section{Comparative statics of market performance}

When firms engage in cost-reducing innovation and then compete à la Cournot in the product market, it is widely recognized that exogenous knowledge spillovers create distortions in $\mathrm{R} \& \mathrm{D}$ investment decisions. In this section, we examine how firms' R\&D levels of investments and net profits vary with the spillover parameter and the cost of performing $R \& D$.

Throughout this subsection, we suppose that Assumptions (A1)-(A4) hold so that the equilibrium pairs of $\mathrm{R} \& \mathrm{D}$ investments $(\bar{x}, \underline{x})$ are interior.

\footnotetext{
${ }^{9}$ Indeed, conditional on being a follower, a firm has a dominant strategy of doing no R\&D, as reflected by a reaction curve identically equal to 0 .
} 


\subsection{Autonomous cost reductions}

An increase in the spillover parameter impacts firms' R\&D expenditures through two channels. Observe first that each firm's payoff is submodular in own R\&D level and $\beta .^{10}$ Hence, the reaction functions shift down as $\beta$ increases, i.e., each firm lowers its $R \& D$ investment as its rival's $R \& D$ level is held constant (this is the direct effect). Intuitively, greater spillovers lower the innovator's benefit from undertaking $R \& D$ as its investment becomes less appropriable, thus enhancing its rival's efficiency in the product market. Likewise, the imitator's incentives to invest in R\&D are undermined since its benefit from free riding over the innovator's R\&D investment is enhanced through greater spillovers.

An increase in the spillover parameter also indirectly impacts firms' investment decisions. Namely, for $\beta \leq \frac{1}{2}$, both firms' payoff functions are submodular in $\left(x_{i}, x_{j}\right)$ so that $\mathrm{R} \& \mathrm{D}$ investments are strategic substitutes. Thus, in this range of the spillover parameter, a decrease in one firm's R\&D makes its rival optimally react by increasing its own level of investment so that it enjoys a competitive advantage over its rival in the product market. This indirect (or strategic) effect works against the direct effect.

Instead, for $\beta>\frac{1}{2}$, the imitator's payoff function is supermodular in the two $R \& D$ levels, so the imitator optimally responds to a decrease in the innovator's level of $\mathrm{R} \& \mathrm{D}$ by lowering its own investment as well. Hence the indirect effect reinforces the direct effect. Intuitively, the larger fraction of $\mathrm{R} \& \mathrm{D}$ that flows to the imitator compensates for the innovator's lower level of investment so that free riding over the innovator's investment is more profitable than undertaking its own R\&D. This emerges due to the new strategic complementarity in the model, in contrast to AW's model.

The next result provides regions of parameters that determine which effect dominates in determining the movement of the two firms' propensities to invest in R\&D. The regions $\underline{\Gamma}$ and $\bar{\Gamma}$ are shown precisely in Figure 3.

Proposition 2. Assume that Assumptions (A1)-(A4) hold, and let $\bar{\Gamma}$ and $\underline{\Gamma}$ be as depicted in Figure 3. Then the following hold:

(i) The innovator's equilibrium REDD level $\bar{x}$ is increasing in $\beta$ if $(\beta, 9 \gamma) \in \bar{\Gamma}$; otherwise it is decreasing.

\footnotetext{
${ }^{10}$ In other words, the cross-partial derivative of each payoff with respect to own $\mathrm{R} \& \mathrm{D}$ level and $\beta$ is weakly negative.
} 
(ii) The imitator's equilibrium REDD level $\underline{x}$ is increasing in $\beta$ if $(\beta, 9 \gamma) \in \underline{\Gamma}$; otherwise it is decreasing.

(iii) Total equilibrium $\operatorname{RED}(\bar{x}+\underline{x})$ is globally decreasing in $\beta$.

(iv) Total effective equilibrium cost reduction $(1+\beta) \bar{x}+(1-\beta) \underline{x}$ is globally decreasing in $\beta$.

Note that the novelty of figure 3 with respect to AW's model is that $\underline{\Gamma}$ almost entirely lies in the part $\beta \leq \frac{1}{2}$, the strategic effect reinforces the direct effect so that the imitator's level of $R \& D$ always decreases with the spillover parameter $\beta$.

Here, we first observe that $(1+\beta) \bar{x}+(1-\beta) \underline{x}$ is the total cost reduction that will be experienced by both firms together, including the autonomous and the spillover portions of R\&D. If one is interested for instance in the average technological progress between the two firms, or in the post $\mathrm{R} \& \mathrm{D}$ state of production efficiency, half of $(1+\beta) \bar{x}+(1-\beta) \underline{x}$ would be the right measure.

The Proposition says that, perhaps not surprisingly, both the total R\&D expenditures and the total effective equilibrium cost reduction are decreasing in $\beta$, suggesting that the eventual rise in one firm's level of R\&D does not compensate for its competitor's lower investment in response to a change in the spillover parameter. Figure 3 displays the regions of parameters $\bar{\Gamma}, \underline{\Gamma}$ for which firms' equilibrium levels of $R \& D$ increase with the spillover rate.

Nevertheless, if either demand is high enough relative to initial unit costs or $R \& D$ cost is sufficiently convex, then the direct effect dominates for both firms: R\&D expenditures globally decrease with the spillover rate. In particular, if $\frac{a}{c}>4$ or $9 \gamma>16,{ }^{11}$ then the innovator's equilibrium level of $R \& D$ is always decreasing in $\beta$. Likewise, if $\frac{a}{c}>2.7$ or $9 \gamma>12,{ }^{12}$ then the imitator's investment in equilibrium $\underline{x}$ is always decreasing in $\beta$, since we focus on an area that entirely lies in the complementarity of $\underline{\underline{\Gamma}}$.

\subsection{Firms' profits}

In this subsection, we investigate the general properties of firms' overall equilibrium profits. In particular, we examine how they vary with both the magnitude of spillovers and the cost of R\&D.

\footnotetext{
${ }^{11}$ This ensures that the graph of $9 \gamma=I(\beta)$, represented by the dashed line in Figure 3 (which shifts upward as $\frac{a}{c}$ rises), lies above $\bar{\Gamma}$ (whose position does not depend on $a$ or $c$ ). In other words, the area of the interior solution entirely lies in the complementarity of $\bar{\Gamma}$.

${ }^{12}$ This ensure that the graph of $9 \gamma=I(\beta)$ lies above $\underline{\Gamma}$.
} 
A long but straightforward computation yields that the equilibrium profits of the innovator and the imitator, corresponding to the equilibrium levels of R\&D (3), are respectively given by

$$
F(\bar{x}, \underline{x})=\frac{(a-c)^{2} \gamma\left(8 \beta-4 \beta^{2}+3 \gamma-4\right)^{2}\left(8 \beta-2 \beta^{2}+9 \gamma-8\right)}{\left(72 \beta \gamma-48 \gamma-40 \beta+32 \beta^{2}-8 \beta^{3}+27 \gamma^{2}-30 \beta^{2} \gamma+16\right)^{2}}
$$

and

$$
F(\underline{x}, \bar{x})=\frac{(a-c)^{2} \gamma\left(6 \beta-2 \beta^{2}+3 \gamma-4\right)^{2}\left(16 \beta-8 \beta^{2}+9 \gamma-8\right)}{\left(72 \beta \gamma-48 \gamma-40 \beta+32 \beta^{2}-8 \beta^{3}+27 \gamma^{2}-30 \beta^{2} \gamma+16\right)^{2}}
$$

Again, two opposite effects need to be considered. On the one hand, as mentioned earlier, greater spillovers lower the imitator's incentives to invest in R\&D in the first stage so as to freely benefit from the innovator's effort. But on the other hand, decreasing its $R \& D$ expenditures exacerbates its production cost disadvantage relative to the innovator at the competition stage, and thus negatively impacts its second-stage profit. Similarly, an increase in $\beta$ alters the innovator's willingness to conduct $\mathrm{R} \& \mathrm{D}$ as its investment becomes less appropriable. However, a decrease in $\mathrm{R} \& \mathrm{D}$ reduces its competitive advantage over its rival, which in turn undermines its profit at the second stage. The next result characterizes regions of parameters for which either effect dominates. The regions $\bar{\Gamma}^{\prime}$ and $\underline{\Gamma}^{\prime}$ are shown in Figure 4.

Proposition 3. Let $\bar{\Gamma}^{\prime}$ and $\Gamma^{\prime}$ be as indicated in Figure 4. Assume that Assumptions (A1)-(A4) hold. Then the innovator's equilibrium profit $F(\bar{x}, \underline{x})$ is increasing in $\beta$ for $\beta<2 / 3$ and $9 \gamma \in \bar{\Gamma}^{\prime}$, while the imitator's profit $F(\underline{x}, \bar{x})$ is decreasing in $\beta$ if $9 \gamma \in \underline{\Gamma}^{\prime}$.

Hence, the innovator's overall profit is increasing with the spillover rate as long as $\beta<\frac{2}{3}$ and $R \& D$ costs are convex enough, meaning that the benefit derived from its competitive advantage over the imitator outweighs the cost of performing $R \& D$. Intuitively, since the imitator lowers its R\&D expenditures, asymmetries across firms in terms of production costs increase at the competition stage and strengthen the innovator's competitive advantage.

However, when $\beta \geq \frac{2}{3}$, the innovator's overall equilibrium profit falls as $\beta$ increases. As the imitator freely benefits from a larger share of the innovator's investment, the efficiency gap between them reduces and negatively impacts the innovator's second-stage profit. As for the imitator, greater spillovers reduce its $R \& D$ investment, which exacerbates its lack of efficiency relative to the innovator in the product market competition. Notably, its equilibrium profit decreases with $\beta$ when the cost of conducting $\mathrm{R} \& \mathrm{D}$ is such that $9 \gamma \in \underline{\Gamma}^{\prime}$. Otherwise, its benefit from free riding over its rival's investment compensates for its competitive disadvantage. 
In particular, when $\beta$ is exactly zero, the symmetry of the firms implies that they both invest a similar amount in R\&D. As $\beta$ departs from zero and $\gamma$ is high enough $(9 \gamma>16)$, we know from Proposition 3 that the equilibrium is asymmetric and both firms face increasing profit functions in $\beta$. Thus both firms are better off with some positive spillover as compared to no spillover, i.e. both profits are higher for small $\beta$ than for $\beta=0$. This is due to the fact that for $\beta<\frac{1}{2}$, if a firm increases its level of R\&D investment, then its rival responds by lowering its own investment, due to the substitutability of R\&D investments. On the innovator's end, this translates into a stronger competitive edge on the product market as its rival reduces investment in $\mathrm{R} \& \mathrm{D}$, although the imitator benefits from low spillover effects. From the imitator's view point, the decrease in competitiveness is more than compensated by the spillover effect from the innovator when costs are high enough. Figure 4 provides a partition of the parameter space which fully illustrates these comparative statics.

Next, we compare both firms' equilibrium profits and find that for $\beta$ near 0 , the innovator's equilibrium profit surpasses that of the imitator, while for $\beta$ close to 1 , the opposite is true. More specifically, as $\beta>\frac{2}{3}$, the imitator's equilibrium profit is greater than the innovator's equilibrium profit, as illustrated by Figure 5, which is reminiscent of the findings in AW. Intuitively, this aligns with the above result regarding the innovator's and the imitator's variations of their overall profit as $\beta$ increases and costs are high enough. The role of endogenous innovator is thus not always favoured, and this impacts the levels of $R \& D$ firms are willing to invest in. These results are summarised in Proposition 4.

Proposition 4. Assume that Assumptions (A1)-(A4) hold. Then the ranking of the innovator's and the imitator's equilibrium profit, $F(\bar{x}, \underline{x})$, and $F(\underline{x}, \bar{x})$ respectively, is given by Figure 5 . In particular, if $\beta \geq 2 / 3$, the imitator obtains a higher equilibrium profit than the innovator.

While this result is quite intuitive, it remains somewhat surprising that being an imitator or low-R\&D firm can be so rewarding when spillovers are high. On the other hand, the threshold of $2 / 3$ being obviously quite high, this result can be expected to hold only in a limited number of possible industries, namely those with very low patent protection, and thus very high spillover potential.

Finally, we consider how equilibrium profits vary with the cost of R\&D. Let $\pi(c)$ denote each firm's profit without any cost reduction, which simply equals per firm Cournot equilibrium profit 
with symmetric unit costs, i.e. $\pi(c)=\frac{1}{9}(a-c)^{2}$. Straightforwardly, both the innovator's and the imitator's profits tend to $\pi(c)$ as $\gamma \rightarrow \infty$. The two sets of graphs in Figure 6 illustrate how each firm's equilibrium profit varies as the cost of $R \& D$ increases for different values of the spillover rate $\beta$. In particular, observe that both the innovator and the imitator are strictly worse off by investing in $\mathrm{R} \& \mathrm{D}$ when $\beta=0.01$ for any value of the cost parameter $\gamma$. The underlying idea is that, for low values of the spillover parameter, firms are engaged in a prisoner's dilemma in the sense that both undertake $R \& D$ in equilibrium while it would be Pareto optimal not to invest at all.

\subsection{Consumer surplus}

Our next result concerns the (unilateral) impacts of an increase in the spillover parameter and in the cost of performing $\mathrm{R} \& \mathrm{D}$ onto consumer surplus.

Proposition 5. Equilibrium consumer surplus is decreasing in both $\beta$ and $\gamma$.

Since total R\&D investments and the resulting total effective cost reductions decrease in both the spillover parameter and the cost of undertaking R\&D (see Proposition 2), it follows that aggregate production costs increase with these two parameters, thereby harming consumers through a higher industry price.

Consequently, despite the fact that individual R\&D levels may increase in the spillover parameter $\beta$, the aggregate effect of an increase in $\beta$ is detrimental to consumers. Therefore, as one would generally expect, the imperfect appropriability of $R \& D$ is detrimental to industry-wide $R \& D$, and thus also to consumer surplus.

As to the overall effects on social welfare, we refer the reader to Cosandier, De Feo and Knauff (2017), which offers a detailed analysis.

\section{Conclusion}

This paper has examined the standard symmetric two-period R\&D model with a deterministic one-way spillover structure. Thus this may be seen as a deterministic analog of the model in AW. ${ }^{13}$ Though firms are ex-ante identical, one obtains a unique asymmetric equilibrium in R\&D

\footnotetext{
${ }^{13}$ For other contexts in which uncertainty and risk affect firms' behavior in strategic settings, see e.g., Jin and Kobayashi (2016) and Sheikh (2017).
} 
investments, so that the roles of $R \& D$ innovator and imitator are endogenously determined. This establishes a simple link between the nature of the $R \& D$ process in an industry -including the associated spillover -and the emergence of inter-firm heterogeneity in that industry.

We analyze the impact of a change in the spillover parameter and R\&D costs on firms' levels of $R \& D$ and profits. While an individual firm's R\&D level may increase in the spillover parameter, this counter-intuitive result cannot happen at the aggregate level.

Therefore, we recover the well-known and extremely robust conclusion that the imperfect appropriability of know-how is detrimental to industry-wide R\&D, and thus also to consumer surplus (for more on this conclusion from an empirical perspective, see Bernstein and Nadiri, 1988 and Griliches, 1995).

As to the comparison of equilibrium profits, we find that, essentially, the innovator obtains more profit for low values of the spillover parameter $(\beta<2 / 3)$, with the opposite holding for large spillover parameters $(\beta \geq 2 / 3)$. It thus emerges that, although it does not always pay to be the R\&D leader, it does under the relevant ranges of the spillover parameter for most industries. 


\section{Appendix (Figures)}
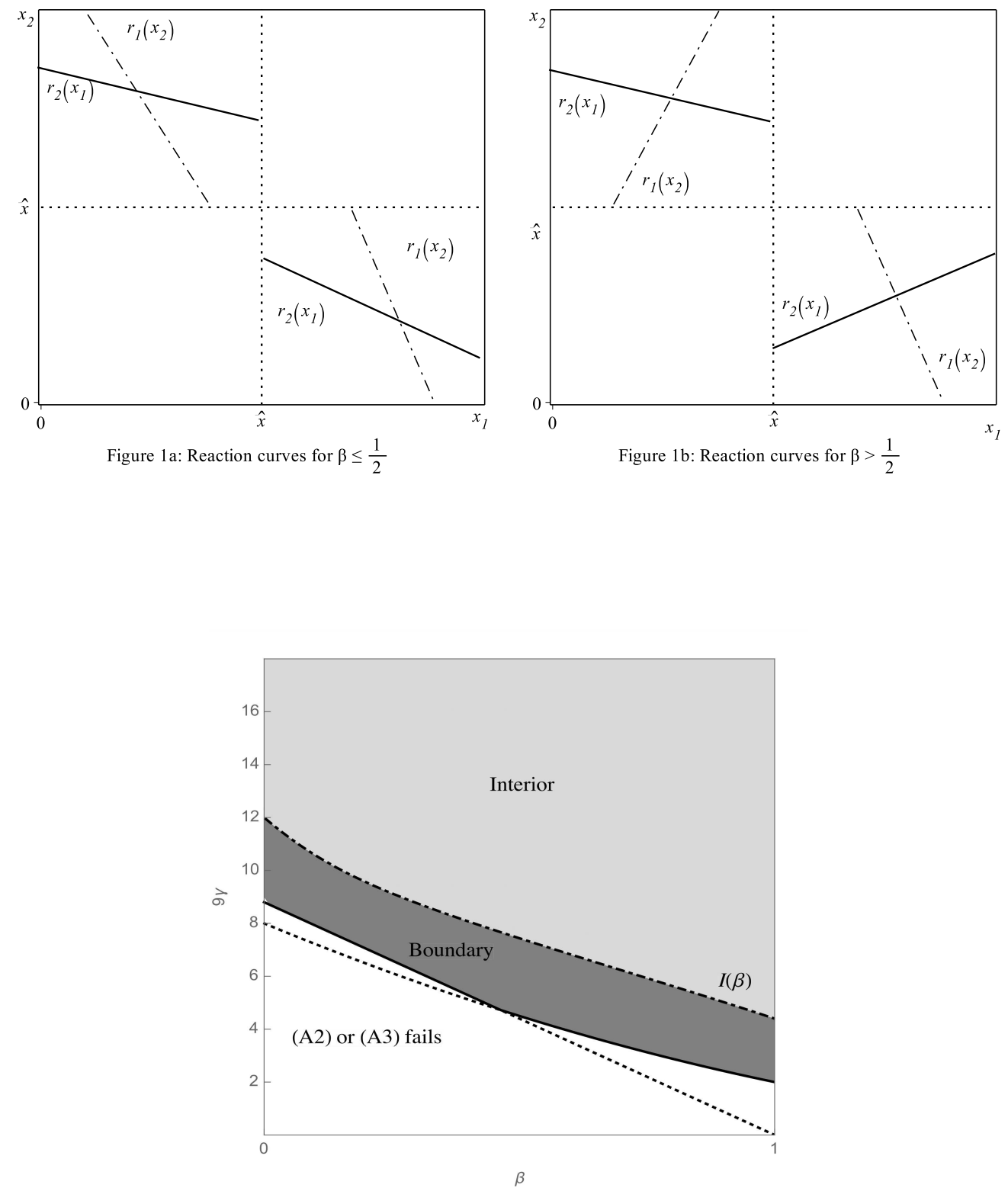

Figure 2: Parameters region for Assumptions (A1)-(A4) 


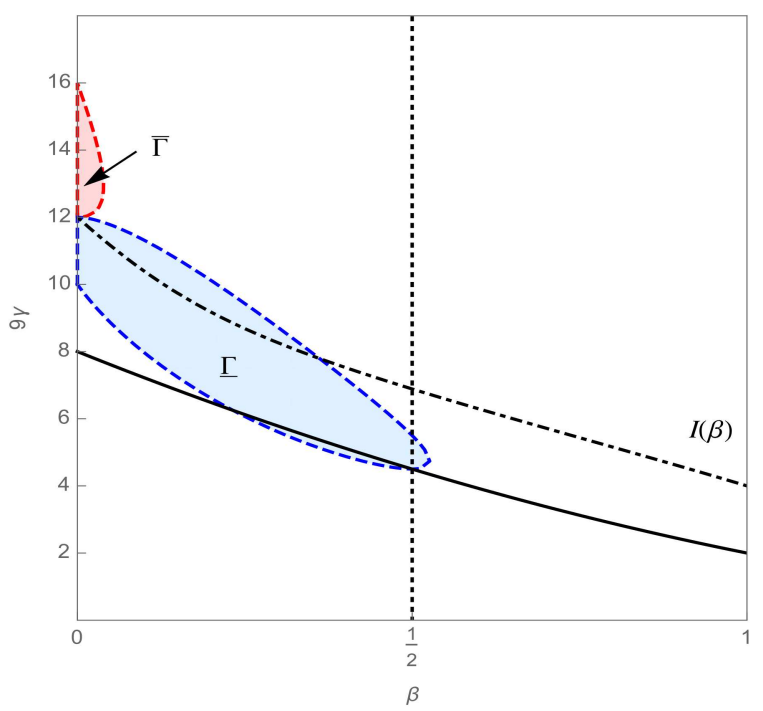

Figure 3: Parameters regions where both the innovator's $(\bar{\Gamma})$ and the imitator's $(\underline{\Gamma})$ equilibrium levels of investment in $\mathrm{R} \& \mathrm{D}$ increase in the spillover parameter $\beta$.

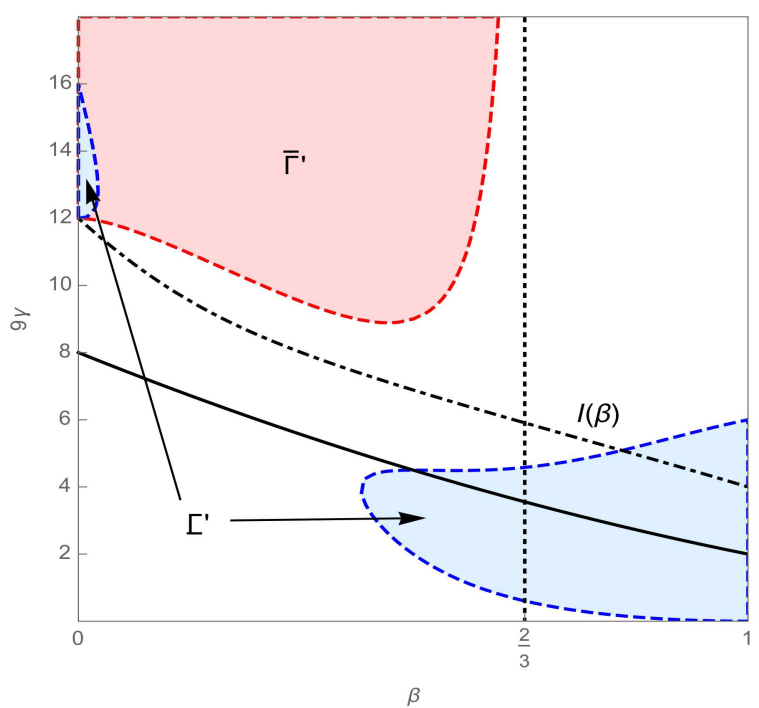

Figure 4: Parameters regions where the innovator's equilibrium profit increases $\left(\bar{\Gamma}^{\prime}\right)$ and the imitator's equilibrium profit decreases $\left(\underline{\Gamma}^{\prime}\right)$ in the spillover parameter $\beta$. 


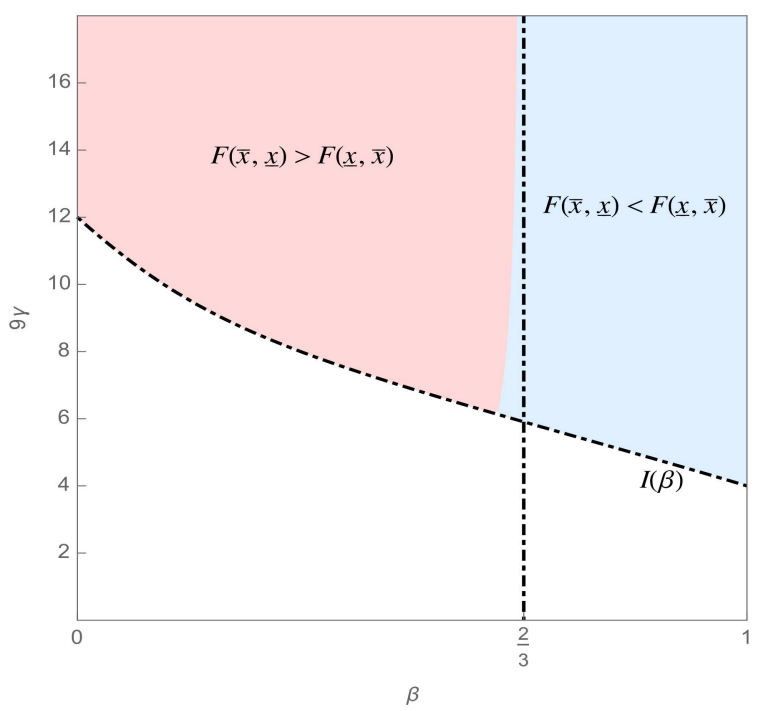

Figure 5: Comparison of the equilibrium profits of the innovator $(F(\bar{x}, \underline{x}))$ and imitator $(F(\underline{x}, \bar{x}))$.

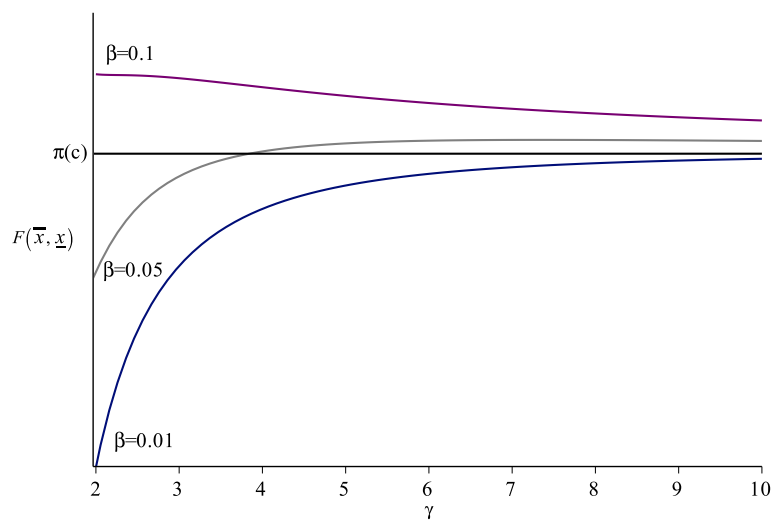

(a) Innovator's equilibrium profit variations

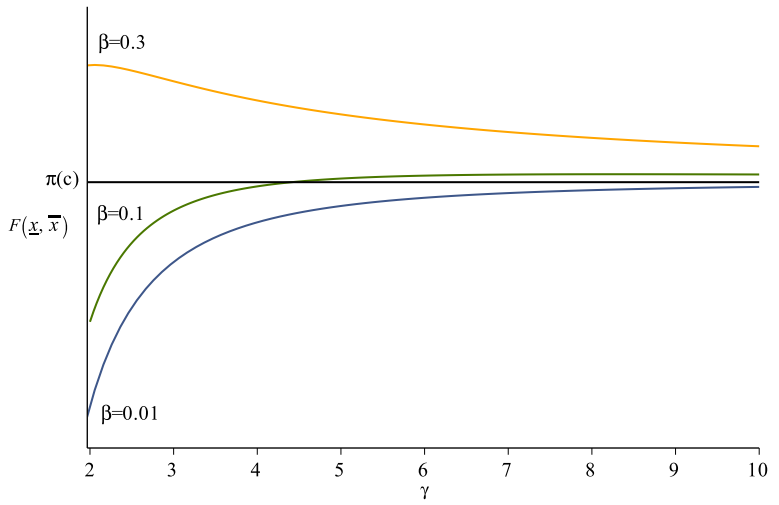

(b) Imitator's equilibrium profit variations

Figure 6: Equilibrium profits variations with the spillover parameter $\beta$. 


\section{Appendix (Proofs)}

\section{Proof of Lemma 1}

The reaction function $r$ as given by Eq. (2) is not continuous since, letting $x^{S 1}=r_{1}\left(x^{S 1}\right)$ for $x_{1} \geq x_{2}$ and $x^{S 2}=r_{1}\left(x^{S 2}\right)$ for $x_{1} \leq x_{2}$, one obtains

$$
\begin{aligned}
x^{S 1} & =\frac{2(a-c)(2-\beta)}{9 \gamma-2(2-\beta)}, \\
x^{S 2} & =\frac{4(a-c)(1-\beta)}{9 \gamma-4(1-\beta)}
\end{aligned}
$$

with $x^{S 1}>x^{S 2}$. Hence, the reaction function has a downward jump, and letting $\widehat{x}$ be the solution to $U\left(r_{1}(\widehat{x}), \widehat{x}\right)=L\left(r_{1}(\widehat{x}), \widehat{x}\right)$, we have that

$$
\widehat{x}=\frac{(a-c)\left(\sqrt{1+\frac{2 \beta(4-3 \beta)}{9 \gamma-2(\beta-2)^{2}}}-1\right)}{2 \beta-1+(1-\beta) \sqrt{1+\frac{2 \beta(4-3 \beta)}{9 \gamma-2(\beta-2)^{2}}}}
$$

It is easy to check that $r_{1}(\widehat{x}) \neq \widehat{x}$. Hence, there cannot exist any symmetric Nash equilibria in pure strategies.

Furthermore, $\hat{x}$ is unique since both $U$ and $L$ are monotonic in $x_{2} . U$ is decreasing in $x_{2}$ for all $\beta \in[0,1]$, while $L$ either increases with $x_{2}$ for $\beta>1 / 2$ or decreases with $x_{2}$ slower than $U$.

\section{Proof of Proposition 1}

A lengthy but simple computation establishes that $\bar{x}, \underline{x}$ as given by Eq. (3) and (4) satisfy $\bar{x}>\widehat{x}$ if $9 \gamma>I_{1}$ and $\underline{x}<\widehat{x}$ if $9 \gamma>I_{2}$, with $\hat{x}$ as defined by Eq. (5) and

$$
\begin{aligned}
& I_{1}=\left(5 \beta^{2}-12 \beta+8\right)+\sqrt{13 \beta^{4}-48 \beta^{3}+68 \beta^{2}-48 \beta+16}, \\
& I_{2}=\left(5 \beta^{2}-12 \beta+8\right)+\sqrt{73 \beta^{4}+224 \beta^{2}-216 \beta^{3}-96 \beta+16},
\end{aligned}
$$

Straightforward computations then establish that $I(\beta)>I_{1}$ and $I(\beta)>I_{2}$. Hence, if assumptions (A1) through (A4) hold, the pair of PSNE $(\bar{x}, \underline{x})$ and $(\underline{x}, \bar{x})$, with $\bar{x}, \underline{x}$ as given by Eq. (3) and (4), is unique.

\section{Proof of Proposition 2}

(i) Differentiating $\bar{x}$ with respect to $\beta$ and collecting terms yields

$$
\frac{d \bar{x}}{d \beta}=-\frac{6(a-c) \gamma L_{1}}{\left(3 \gamma\left[9 \gamma-2\left(5 \beta^{2}-12 \beta+8\right)\right]+8(2-\beta)(\beta-1)^{2}\right)^{2}}
$$


where $L_{1}=27 \gamma^{2}-6 \gamma\left(13 \beta^{2}-28 \beta+14\right)+8\left(5 \beta^{2}-12 \beta+8\right)(\beta-1)^{2}$. Thus, $\frac{d \bar{x}}{d \beta}>0$ if and only if $L_{1}<0$, which holds for $(\beta, 9 \gamma)$ such that $\beta<0.04$ and $9 \gamma \in \bar{\Gamma}=\left(\gamma_{1}(\beta), \gamma_{2}(\beta)\right)$, where

$$
\begin{aligned}
& \gamma_{1}(\beta)=13 \beta^{2}-28 \beta-\sqrt{260 \beta^{2}-112 \beta-200 \beta^{3}+49 \beta^{4}+4}+14 \\
& \gamma_{2}(\beta)=13 \beta^{2}-28 \beta+\sqrt{260 \beta^{2}-112 \beta-200 \beta^{3}+49 \beta^{4}+4}+14
\end{aligned}
$$

(ii) In a similar fashion, differentiating $\underline{x}$ with respect to $\beta$ and collecting terms yields

$$
\frac{d \underline{x}}{d \beta}=-\frac{12(a-c) \gamma L_{2}}{\left(3 \gamma\left[9 \gamma-2\left(5 \beta^{2}-12 \beta+8\right)\right]+8(2-\beta)(\beta-1)^{2}\right)^{2}},
$$

where $L_{2}=27 \gamma^{2}-6 \gamma\left(4 \beta^{2}-14 \beta+11\right)+4(\beta-1)\left(18 \beta-15 \beta^{2}+5 \beta^{3}-10\right)$. Thus, $\frac{d x}{d \beta}>0$ if and only if $L_{2}<0$, which holds if $(\beta, 9 \gamma)$ is such that $9 \gamma \in \underline{\Gamma}=\left(\gamma_{3}(\beta), \gamma_{4}(\beta)\right)$, where

$$
\begin{aligned}
& \gamma_{3}(\beta)=\left(4 \beta^{2}-14 \beta+11\right)-\sqrt{28 \beta-112 \beta^{2}+128 \beta^{3}-44 \beta^{4}+1} \\
& \gamma_{4}(\beta)=\left(4 \beta^{2}-14 \beta+11\right)+\sqrt{28 \beta-112 \beta^{2}+128 \beta^{3}-44 \beta^{4}+1}
\end{aligned}
$$

(iii) The sum of autonomous cost reductions is given by

$$
\frac{d}{d \beta}(\bar{x}+\underline{x})=\frac{6 \gamma(a-c) L_{3}}{\left(3 \gamma\left[9 \gamma-2\left(5 \beta^{2}-12 \beta+8\right)\right]+8(2-\beta)(\beta-1)^{2}\right)^{2}}
$$

where

$$
L_{3}=-81 \gamma^{2}+6 \gamma\left(21 \beta^{2}-56 \beta+36\right)+16(1-\beta)\left(19 \beta-16 \beta^{2}+5 \beta^{3}-9\right)<0 \text { for all } \beta \in[0,1]
$$

It is easy to verify that the sum $(\bar{x}+\underline{x})$ is decreasing in $\beta$.

(iv) As to the fact that $(1+\beta) \bar{x}+(1-\beta) \underline{x}$ is also decreasing in $\beta$, a direct computation shows that $\frac{d}{d \beta}((1+\beta) \bar{x}+(1-\beta) \underline{x})<0$ (the details are left out).

\section{Proof of Proposition 3}

(i) From Eq. (1), the innovator's equilibrium profit is given by

$$
F(\bar{x}, \underline{x})=\frac{(a-c+\bar{x}(2-\beta)-\underline{x}(1-\beta))^{2}}{9}-\frac{\gamma}{2} \bar{x}^{2}
$$


Plugging $\bar{x}$ and $\underline{x}$ as given by Eq. (3) and (4) and differentiating totally $F(\bar{x}, \underline{x})$ with respect to $\beta$ yields

$$
\frac{d}{d \beta} F(\bar{x}, \underline{x})=-\frac{12\left(3 \gamma-4(1-\beta)^{2}\right) \gamma^{2}(a-c)^{2} L_{4}}{\left(3 \gamma\left[9 \gamma-2\left(5 \beta^{2}-12 \beta+8\right)\right]+8(2-\beta)(\beta-1)^{2}\right)^{3}}
$$

where $L_{4}=27 \gamma^{2}(3 \beta-2)-6 \gamma\left(13 \beta^{3}-48 \beta^{2}+58 \beta-22\right)+8\left(5 \beta^{3}-16 \beta^{2}+20 \beta-10\right)(1-\beta)^{2}$. Under assumption (A4), the denominator is strictly positive and $3 \gamma>4(1-\beta)^{2}$ for any $\beta \in[0,1]$. Therefore, we have that $\frac{\mathrm{d}}{\mathrm{d} \beta} F(\bar{x}, \underline{x})>0$ if and only if $L_{4}<0$, which holds for $\beta<2 / 3$ and $9 \gamma \in \bar{\Gamma}^{\prime}=\left(\gamma_{5}(\beta), \infty\right)$, where

$\gamma_{5}(\beta)=\frac{22-58 \beta+48 \beta^{2}-13 \beta^{3}+\sqrt{4+88 \beta-572 \beta^{2}+1348 \beta^{3}-1540 \beta^{4}+864 \beta^{5}-191 \beta^{6}}}{(2-3 \beta)}$.

(ii) Likewise, the imitator's equilibrium profit is given by

$$
F(\underline{x}, \bar{x})=\frac{(a-c+2 \underline{x}(1-\beta)+\bar{x}(2 \beta-1))^{2}}{9}-\frac{\gamma}{2} \underline{x}^{2}
$$

Differentiating totally $F(\underline{x}, \bar{x})$ with respect to $\beta$ yields

$$
\frac{d}{d \beta} F(\underline{x}, \bar{x})=\frac{12(a-c)^{2}(3 \gamma-2(1-\beta)(2-\beta)) \gamma^{2} L_{5}}{\left(3 \gamma\left[9 \gamma-2\left(5 \beta^{2}-12 \beta+8\right)\right]+8(2-\beta)(\beta-1)^{2}\right)^{3}},
$$

where $L_{5}=27 \gamma^{2}+6 \gamma\left(-14+40 \beta-45 \beta^{2}+16 \beta^{3}\right)-8\left(-8+24 \beta-27 \beta^{2}+10 \beta^{3}\right)(1-\beta)^{2}$. Again, if (A4) holds, the denominator is strictly positive and $3 \gamma>2(1-\beta)(2-\beta)$ for any $\beta \in[0,1]$. Hence, the imitator's profit is strictly decreasing in $\beta$ if and only if $L_{5}<0$, which holds for $9 \gamma \in \underline{\Gamma}^{\prime}=\left(\gamma_{6}(\beta), \gamma_{7}(\beta)\right)$, where

$$
\begin{aligned}
& \gamma_{6}(\beta)=45 \beta^{2}-40 \beta-16 \beta^{3}+14-\sqrt{868 \beta^{2}-160 \beta-1936 \beta^{3}+2177 \beta^{4}-1200 \beta^{5}+256 \beta^{6}+4} \\
& \gamma_{7}(\beta)=45 \beta^{2}-40 \beta-16 \beta^{3}+14+\sqrt{868 \beta^{2}-160 \beta-1936 \beta^{3}+2177 \beta^{4}-1200 \beta^{5}+256 \beta^{6}+4}
\end{aligned}
$$

\section{Proof of Proposition 4}

Under (A1)-(A4), computations show that the inequality $F(\bar{x}, \underline{x})>F(\underline{x}, \bar{x})$ in the light red area is defined by the inequalities $9 \gamma>I(\beta), 0<\beta<2 / 3$, and $9 \gamma>\frac{6(1-x)^{2}(4-5 x)}{2-3 x}$. Likewise, $F(\bar{x}, \underline{x})<F(\underline{x}, \bar{x})$ in the light blue area is defined by the inequalities $9 \gamma>I(\beta)$ and either $(1)$ $0<\beta<2 / 3$, and $9 \gamma<\frac{6(1-x)^{2}(4-5 x)}{2-3 x}$ or $(2) \beta \geq 2 / 3$. 


\section{Proof of Proposition 5}

Consumer surplus at the noncooperative interior equilibrium reduces to

$$
C S(\bar{x}, \underline{x})=\frac{18(3 \gamma+(1-\beta)(3 \beta-4))^{2}(a-c)^{2} \gamma^{2}}{\left(27 \gamma^{2}-6 \gamma\left(5 \beta^{2}-12 \beta+8\right)-8(\beta-2)(\beta-1)^{2}\right)^{2}}
$$

Differentiating $C S(\bar{x}, \underline{x})$ with respect to $\beta$ yields

$$
\frac{d}{d \beta} C S(\bar{x}, \underline{x})=\frac{36 \gamma^{2}(a-c)^{2} K_{1} K_{2}}{\left(27 \gamma^{2}-6 \gamma\left(5 \beta^{2}-12 \beta+8\right)-8(\beta-2)(\beta-1)^{2}\right)^{3}}
$$

where

$$
K_{1}=9 \gamma^{2}(2 \beta-3)+6 \gamma\left(11 \beta^{2}-24 \beta+12\right)-8\left(3 \beta^{2}-8 \beta+6\right)(\beta-1)^{2}
$$

and

$$
K_{2}=3 \gamma-(1-\beta)(4-3 \beta) .
$$

We have that $K_{1} \cdot K_{2}<0$ since $K_{1}<0$ and $K_{2}>0$ for all $9 \gamma>I(\beta)$. Since the denominator is strictly positive, it follows that $\frac{d}{d \beta} C S(\bar{x}, \underline{x})<0$.

Likewise, we have that

$$
\frac{d}{d \gamma} C S(\bar{x}, \underline{x})=-\frac{36(a-c)^{2} \gamma K_{2} K_{3}}{\left(27 \gamma^{2}-6 \gamma\left(5 \beta^{2}-12 \beta+8\right)-8(\beta-2)(\beta-1)^{2}\right)^{3}},
$$

where

$$
K_{3}=9 \gamma^{2}\left(\beta^{2}-3 \beta+4\right)-48 \gamma(2-\beta)(1-\beta)^{2}-8(3 \beta-4)(2-\beta)(1-\beta)^{3} .
$$

Observe that $K_{2} \cdot K_{3}>0$ since $K_{2}>0$ and $K_{3}>0$ for all $9 \gamma>I(\beta)$. Hence, $\frac{d}{d \gamma} C S(\bar{x}, \underline{x})<0$.

\section{References}

[1] Acemoglu, D., J. Robinson and T. Verdier (2017). Asymmetric growth and institutions in an interdependent world, Journal of Political Economy, 125, 1245-1305.

[2] Amir, R. (2000). Modelling imperfectly appropriable R\&D via spillovers. International Journal of Industrial Organization, 18: 1013-1032.

[3] Amir, R., I. Evstigneev, J. Wooders (2003). Noncooperative versus cooperative R\&D with endogenous spillover rates, Games and Economic Behavior 42, 183-207. 
[4] Amir, R., Wooders, J. (1999). Effects of one-way spillovers on market shares, industry price, welfare, and R\&D cooperation. Journal of Economics and Management Strategy, 8: 223-249.

[5] Amir, R., C. Halmenschlager and M. Knauff (2017). Does the cost paradox preclude technological progress under imperfect competition? Journal of Public Economic Theory, 19, $81-96$

[6] Amir, R., F. Garcia and M. Knauff (2010). Symmetry-breaking in two-player games via strategic substitutes and diagonal nonconcavity: A synthesis, Journal of Economic Theory 145, 1968-1986.

[7] Basu, K., Basu and T. Cordella (2016), Asymmetric punishment as an instrument of corruption control, Journal of Public Economic Theory, 18, 831-856.

[8] Bernstein, J. and I. Nadiri (1988). Interindustry R\&D spillovers, rates of return, and production in high-tech industries. American Economic Review 78, 429-34.

[9] Billand, P., C. Bravard, S. Chakrabarti and S. Sarangi (2016). Business intelligence and multimarket competition, Journal of Public Economic Theory, 18, 248-267.

[10] Burr, C., Knauff, M., Stepanova, A. (2013). On the prisoner's dilemma in R\&D with input spillovers and incentives for R\&D cooperation. Mathematical Social Sciences, 66: 254-261.

[11] Chalioti, E. (2015). Incentive contracts under product market competition and R\&D spillovers. Economic Theory, 58: 305-328.

[12] Chatterjee, A. (2017). Endogenous comparative advantage, gains from trade and symmetrybreaking, Journal of International Economics, 109, 102-115.

[13] Cosandier, C., De Feo, G., Knauff, M. (2017). Equal treatment and socially optimal R\&D in duopoly with one-way spillovers, Journal of Public Economic Theory, 19, 1099-1117.

[14] d'Aspremont, C., Jacquemin, A. (1988). Cooperative and noncooperative R\&D in duopoly with spillovers. American Economic Review, 78: 1133-1137.

[15] d'Aspremont, C., Jacquemin, A. (1990). Erratum. American Economic Review, 80: 641-642. 
[16] Griliches, Z. (1995). R\&D and productivity: Econometric results and productivity issues, in P. Stoneman ed., Handbook of the Economics of Innovation and Technological Change, Basil Blackwell, Oxford.

[17] Hinloopen, J. (1997). Subsidizing cooperative and noncooperative R\&D in duopoly with spillovers, Journal of Economics 66, 151-175.

[18] Jin, J. Y. , S. Kobayashi (2016). Impact of risk aversion and countervailing tax in oligopoly, Annals of Finance, 12, 393-408.

[19] Jin, J.Y., Troege, M. (2006). R\&D competition and endogenous spillovers. The Manchester School, 74: 40-51.

[20] Kamien, M., Muller, E., Zang, I. (1992). Research joint ventures and R\&D cartels. American Economic Review, 82: 1293-1306.

[21] Katz, M. (1986). An analysis of cooperative research and development. RAND Journal of Economics, 17: 527-543.

[22] Martin, S. (2002). Spillovers, appropriability and R\&D. Journal of Economics, 75: 1-22.

[23] Matsuyama, K. (2002). Explaining diversity: symmetry-breaking in complementarity games, American Economic Review, 92, 241-246.

[24] McDonald, S., Poyago-Theotoky, J. (2017). Green technology and optimal emissions taxation. Journal of Public Economic Theory, 19(2), 362-376.

[25] Ruff, L. (1969). Research and technological progress in a Cournot economy. Journal of Economic Theory, 1: 397-415.

[26] Salant, S. W., Shaffer, G. (1998). Optimal asymmetric strategies in research joint ventures. International Journal of Industrial Organization, 16: 195-208.

[27] Salant, S. W., Shaffer, G. (1999). Unequal treatment of identical agents in Cournot equilibrium. American Economic Review, 89: 585-604.

[28] Sheikh, S. (2017). Threat of termination and firm innovation, Annals of Finance, 13, 75-95. 
[29] Soubeyran, A. and N. Van Long (1999). Asymmetric contributions to research joint ventures. The Japanese Economic Review 50, 122-137.

[30] Spence, M. (1984). Cost reduction, competition, and industry performance. Econometrica 52, 101-121.

[31] Spencer, B.J., J.A. Brander (1985). International R\&D rivalry and industrial strategy. The Review of Economic Studies 50, 707-722.

[32] Stepanova, A., Tesoriere (2011). R\&D with spillovers: monopoly versus noncooperative and cooperative duopoly, The Manchester School 79, 125-144.

[33] Tesoriere, A. (2008). Endogenous R\&D symmetry in linear duopoly with one-way spillovers. Journal of Economic Behavior \& Organization 66: 213-225. 